\title{
A contribuição do ensino problematizador de Majmutov na formação por etapas das ações mentais de Galperin
}

\author{
The contribution of teaching problem solving of Majmutov in \\ formation by stages of mental actions of Galperin
}

Héctor José García Mendoza1
Oscar Tintorer Delgado2

\section{RESUMO}

As estratégias didáticas de ensino devem ter em conta as teorias de aprendizagem como fundamento psicológico do processo de assimilação. Na evolução da teoria Histórico Cultural, iniciada por Vygotsky, se desenvolveram vários conceitos como: a zona de desenvolvimento proximal, a Atividade, a formação por etapas das ações mentais e os conceitos e o Ensino Problematizador. O artigo pretende articular a proposta de ensino problematizador de Majmutov com o processo de assimilação e sua direção desenvolvido por Galperin. Considerando que o processo de aprendizagem passa por ações materiais e sociais até chegar a ações mentais e individuais, a proposta de Galperin permite um bom planejamento didático com etapas de orientação por parte do professor e por etapas de execução, explicação, generalização e automatização das atividades pelo estudante que garantem aprendizagem consciente na medida que são cumpridos os objetivos de cada etapa com independência. Para Galperin e seus colaboradores um procedimento eficaz neste processo é a resolução de problemas e por isto existe uma aproximação com Majmutov, que fundamenta sua proposta didática na filosofia materialista dialética e na psicologia histórico cultural explicitando com mais precisão como construir o problema docente e os processos de solução lógicos - analíticos e heurísticos que não se

\begin{abstract}
Didactic teaching strategies should take into account the learning theories and psychological foundation of the assimilation process. In the evolution of Cultural History theory, initiated by Vygotsky, will develop several concepts such as the zone of proximal development, the activity, the formation in stages of mental actions and concepts and problem-solving education. The article aims pronounce Majmutov proposal on problematizing education with assimilation process and the direction process developed by Galperin. Considering the learning process goes through material and social actions to reach mental and individual, the proposal Galperin allows good educational planning stages of guidance by the teacher and execution stages, explanation, generalization and automation of activities per student to ensure learning conscious to the extent that the objectives of each stage are met independently. To Galperin and his colleagues an effective procedure in this process is the resolution of problems and that there is an approach to Majmutov, which bases its didactic proposal in dialectical materialist philosophy and cultural history psychology explaining precisely how to build teaching problem and the processes logical solution analytical and heuristic that is not in a Galperin. The authors propose the Activity Problem Situations formed of four actions and exemplifying.
\end{abstract}

\footnotetext{
${ }^{1}$ Doutor em Educação. Professor do departamento de Matemática da UFRR e dos Programas de Pós-Graduação em Ensino de Ciências (UERR) e em Educação em Ciências e Matemática da Rede Amazônica de Educação em Ciências e Matemática. Email: hector.mendoza@ufrr.br

${ }^{2}$ Doutor em Ciências Técnicas. Professor do departamento de Física e dos Programas de PósGraduação em Ensino de Ciências (UERR) e em Educação em Ciências e Matemática da Rede Amazônica de Educação em Ciências e Matemática. Email: tintorer@bol.com.br.
} 
encontram em Galperin. Os autores propõem a Atividade de Situações Problema formada por quatros ações e exemplificam.
Keywords: Teaching problem solving. Formation of mental actions. Activity theory.

Palavras-chave: Ensino problematizador. Formação das ações mentais. Teoria da atividade.

\section{Introdução}

Os enormes desafios socioambientais que a humanidade enfrenta atualmente exigem cada vez mais uma população com uma cultura científica para poder entender os complexos processos do mundo natural e o social e tomar decisões apropriadas.

A evolução da espécie humana dotou sua psique da consciência, que potencializa o homem com o poder da criação. Os seres humanos são capazes de refletir o mundo material e recriá-lo. Cabe à sociedade e especialmente à escola realizar um projeto político pedagógico que priorize o desenvolvimento da criatividade.

Ainda que a formação de personalidades criativas dependa de vários fatores é dever da comunidade escolar oferecer oportunidades a todos de desenvolvê-las. Um ensino problematizador cria as condições para isso.

Partindo dos princípios do materialismo dialético; teoria da atividade de Léontiev na zona de desenvolvimento proximal de Vygotsky; tomando como centro da organização do ensino a teoria da formação por etapas das ações mentais e ou conceitos de Galperin e considerando a interação entre o objeto e sujeito controlada, avaliada e corrigida por etapas; utilizando os princípios exposto por Rubinstein que o processo mental está relacionado com a solução de problema; Majmutov o ensino problematizador como uma metodologia para a aprendizagem, portanto os autores deste artigo constroem a Atividade de Situações Problema.

O processo ensino aprendizagem deve estar centrado no ensino problematizador através da Atividade de Situações Problema, que está formada pelo sistema de quatro ações invariantes: formular o problema docente, construir 
o núcleo conceitual, solucionar o problema docente e interpretar a solução. A atividade mencionada é mediada pela direção da atividade de estudo proposta por Talízina.

$\mathrm{O}$ artigo tem por objetivo articular a proposta de ensino problematizador de Majmutov com o processo de assimilação e sua direção desenvolvido por Galperin. Se apresentam os fundamentos filosóficos, psicológicos e didáticos para o desenvolvimento de um processo de ensino aprendizagem centrado na resolução de problemas com base na teoria Histórico Cultural iniciada por Vygotsky com ênfase nos trabalhos de Galperin e sua teoria da formação das ações mentais e os conceitos e de Majmutov com sua proposta de ensino problematizador. Sobre esse fundamento, os autores apresentam exemplos de como construir alguns tipos de situações problemas que potencializem o trabalho independente e contribuam para que os estudantes aprendam conhecimentos uteis para sua vida cidadã e avancem no desenvolvimento de sua consciência.

$\mathrm{O}$ artigo começa apresentando os fundamentos gnosiológico e psicológicos fundamentados nas ideias de Majmutov e Rubinstein, seguidamente a teoria de formação por etapas das ações mentais e conceitos de Galperin, posteriormente é definido o problema docente segundo Majmutov. Por último é construído a Atividade de Situações Problema a partir das aproximações do ensino problematizador de Majmutov e o processo de assimilação de Galperin.

\section{As contradições do conhecimento no processo de ensino ${ }^{3}$}

Segundo Majmutov (1980, p. 32-34) as leis do materialismo dialético fornecem os fundamentos filosóficos para o estudo do processo de ensino aprendizagem. Portanto, a dialética do processo de aprendizagem escolar, o avanço do processo de assimilação e o desenvolvimento intelectual, podem revelar-se através da lógica dialética (principalmente na teoria do reflexo e na unidade e luta de contrários) como método do conhecimento da realidade.

Ainda que existem diferentes tipos de reflexos, o que interessa neste artigo é o reflexo humano subdividido no direto ou sensorial e no indireto ou lógico e ele

${ }^{3}$ Neste item está fundamentado em Majmutov (1983, p. 34 - 118) 
pode ser antecipado. A fonte do reflexo é a realidade, mas a través de processos psíquicos, que dependem principalmente da experiência acumulada, o ser humano tem diferentes percepções da mesma realidade. Tal é assim, que ele tem as habilidades do reflexo criador constituindo o mais alto nível de sua capacidade intelectual, pois cria novos elementos materiais e espirituais para a sociedade. (MAJMUTOV, 1983, p. 32-42)

A relação da experiência sensorial com a essência revelada nos conceitos, constitui uma importante condição da unidade do sensorial e o racional. Esta unidade se relaciona com o pensamento, cujo nível, igual ao nível do conhecimento racional, se determina pelo grau de generalização dos conceitos. Portanto, o processo do conhecimento é o reflexo dos objetos e fenômenos da realidade na consciência humana incluindo a atividade transformadora e criadora do homem (MAJMUTOV, 1983, p. 38-39).

O processo de formação de conceito deve passar por três etapas: que pode iniciar-se através da observação ou da experiência, seguidamente são reelaborados os dados logicamente para produzir abstrações que permitem por último a generalização para construir as propriedades essências dos conceitos (MAJMUTOV, 1983, p. 42).

Majmutov (1983, p. 43) propõe decompor o conhecimento não em sensorial e racional, senão em empírico e teórico. O sensorial e racional se refere as formas e os níveis dos conhecimentos, enquanto, o empírico e teórico se refere aos níveis do processo cognoscitivo. O empírico está relacionado com a prática através da observação, a descrição, mediação e o experimento que serve de base para manifestar regularidades. O teórico está vinculado com abstração com a busca de princípios e leis.

No processo de ensino aprendizagem, na disseminação e produção de conhecimentos, surgem diferentes contradições o que gera diversas situações problema; cuja solução permite o desenvolvimento cognitivo de todos os envolvidos. Segundo Majmutov "a correta estruturação do conteúdo e os métodos de ensino, dependem da correta solução de um dos problemas mais complexos da didática, a correlação entre o conhecimento e a atividade” (1983, p. 44) 
Majmutov comenta que "quando o conhecimento e as atividades se conjugam, considerando a atividade como reitora se manifestam as seguintes possibilidades: a) certa assimilação primeiro e despois aplicação; b) a assimilação e a aplicação são dois aspetos único do conhecimento" (1983, p. 44).

Tendo em conta as anteriores possibilidades desenvolvidas pela pedagogia, Majmutov (1883, p. 45) construiu o procedimento didático central estabelecendo que: unicamente a solução das contradições que aparecem no processo de ensino, durante a aprendizagem, podem constituir o processo adequado de assimilação criadora do estudante de ditos conhecimentos e os atos que com elas se relacionam.

Majmutov define "o problema é uma forma subjetiva de expressar a necessidade de desenvolver o conhecimento científico. Este é o reflexo de uma situação problema, ou seja, de uma contradição entre o conhecimento e falta de conhecimento que objetivamente surge do processo social” (1983, p. 58).

Assim a proposta de Majmutov tem fundamento gnosiológico, psicológico e didático

Se pode concluir que as capacidades cognoscitivas do estudante no ensino, pode revelar-se no sistema de categoria da gnosiologia (o reflexo, a contradição, o problema e a hipóteses, etc.), da psicologia (situação problema, o pensamento, intuição, etc.) da didática (o procedimento e método de ensino, o problema docente, etc.) e de outras ciências que expliquem os mecanismos da atividade criativa do homem. (MAJMUTOV, 1983, p. 87, tradução nossa).

Nosso conhecimento da realidade objetiva dá início com as sensações e as percepções, mas não acaba com elas e daí passa para o pensamento. Partindo das sensações e as percepções, o pensamento supera os limites do sensorial - intuitivo e amplia o campo do nosso conhecimento. O descobrimento das relações e conexões entre os objetos é uma tarefa essencial do pensamento e través das relações o conhecimento é cada vez mais profundo (RUBINSTEIN, 1967, p. 378).

A prática segue sendo a base e o critério para a atitude do pensamento; o pensamento teórico segue dependendo da prática. O pensamento teórico está vinculado à atividade, é por si mesmo um processo, um passo ou uma transição do individual ao geral e do geral ao individual, do fenômeno ao essencial e do essencial ao fenômeno. O pensamento realmente existente é o desenvolvimento 
de ideias, como uma unidade entre a atividade e o resultado, do processo e de seu conteúdo, do pensar e do pensamento (RUBINSTEIN, 1967, p. 380).

Todo processo mental, é por sua estrutura, um ato mental orientado para a solução de uma determinada tarefa ou um determinado problema com a finalidade de uma atividade mental do indivíduo, na qual está vinculada com as condições da formulação do problema. O fator inicial do processo mental é, por regra geral, a situação problema. O homem começa a pensar quando sente a necessidade de compreender algo. O pensar começa normalmente com o problema ou com uma questão, com um assombro ou com uma confusão, com uma contradição. Toda situação problema conduz a que se inicie o processo mental e está orientado a solução de qualquer problema (RUBINSTEIN, 1967, p. 386).

Para resolver um problema mediante um processo mental deve-se chegar a um adequado conhecimento. O pensamento recorre a comparação, as análises e sínteses, a abstração e a generalização que formam vários aspectos do processo mental vinculados entre si e se fundem um com outro descobrindo nexos e relações cada vez mais objetivos (RUBINSTEIN, 1967, p. 393-394).

O processo real do pensamento criador é inseparável da intuição, que é compreendido como uma conjetura baseada nos conhecimentos e experiência pessoal onde faltam determinadas etapas de forma precisas. O fundamento do enfoque intuitivo para resolver quaisquer problemas, tanto no diz respeita a criatividade do estudante como o cientifico, é a acumulação de conhecimento e domínio de experiências de atividade criadora sobre a base de achar variados procedimentos e resolver tarefas, incluindo um elevado nível de dificuldades psicológicas, relacionada com a necessidade de descobrir soluções intuitivas inesperadas (MAJMUTOV, 1983, p. 107).

Para a solução de problemas relacionados ao conhecimento existem dois procedimentos analítico-lógico e/ou heurístico. O procedimento analítico - lógico da atividade mental se relaciona ao resolver problema através de algoritmo de solução. As análises e sínteses, a generalização e abstração e concretização são operações mentais que sucedem uma atrás da outra em ordem determinando, como etapas, elevando-se cada vez em busca da solução do problema. O 
pensamento heurístico está relacionado com o pensamento intuitivo, a busca dos procedimentos de solução é através da formulação de hipóteses, geralmente usando a intuição, como resultado de uma conjetura repentina (MAJMUTOV, 1983, p. 108 - 109).

O pensamento criador se relaciona com uma determinada estrutura de busca mental, e com uma série de atos intelectuais consecutivos, encaminhados à formulação e solução do problema que consiste nas seguintes etapas: a) surgimento da situação problema e formulação do problema, b) a utilização dos procedimentos de solução conhecidos ou solução fechada do problema, c) ampliação de busca de novos procedimentos de solução ou solução aberta do problema para a descoberta de nova relação ou princípio da ação e d) a comprovação do grau de correção da solução (MAJMUTOV, 1983, p. 114).

A situação problema se descreve como o ponto de partida do pensamento, não deve entender-se o problema existente já concluso desde o princípio, sem que antes houvesse chegado à reflexão e que o processo mental se inicie despois de haver-se formulado o problema. A situação problema pode surgir com sentimento de assombro, no plano da ação ou solução de uma tarefa cognoscitiva e na realização do próprio trabalho prático (RUBINSTEIN, 1967, p. 391).

A situação problema e o problema são diferentes. A situação problema depende do estado psíquico de alguma experiência e não pode ser expresso externamente, ou seja, tem como fundamento a relação entre os conhecimentos assimilados e os que o sujeito pretende assimilar. O problema é uma expressão linguística, verbal que pode manifestar-se em forma de pergunta ou exercício e é resultado de análise da situação problema sobre a base do ato da objetivação (RUBINSTEIN, 1967; MAJMUTOV, 1983).

A solução do problema tem quase sempre por premissa os conhecimentos teóricos, cujo conteúdo generalizado supera em muito os limites da situação intuitiva. Primeiramente se tenta relacionar de modo impreciso o problema formulado com determinado campo do saber (RUBINSTEIN, 1967, p. 392).

A análise da situação problema, do conhecido e o desconhecido, de seus nexos e relações, conduz as sínteses e generalização à formulação do problema. Quando o problema se há formulado como uma tarefa, em que por separado 
aparece os dados e incógnitas, as condições e os requisitos, o pensamento se determina pela correlação entre as tarefas e os requisitos. Nesta correlação consiste precisamente no processo mental de solução da tarefa (MAJMUTOV, 1983, p. 118).

Num primeiro momento tenta-se utilizar a solução cerrada do problema à busca da relação do conhecido e o desconhecido utilizando as experiências anteriores, sendo os procedimentos mais comuns os analíticos ou lógicos como a analogia ou transferência. Se não for possível dar solução ao problema são usados os procedimentos abertos, que consiste em encontrar novas relações entre o conhecido e o desconhecido através da intuição e formulação de hipóteses que finalmente deve ser comprovada. Destaca-se a relação entre o conhecido e desconhecido deve acontecer na Zona de Desenvolvimento Proximal.

\section{Teoria de formação por etapas das ações mentais e conceitos de Galperin}

$\mathrm{Na}$ teoria histórica cultural de Vygotsky, o processo de assimilação do homem está dado pela experiência social. Vygotsky, Leóntiev e Galperin entre outros reconhecem a natureza social da atividade interna (psíquica) do homem e sua unidade com a atividade externa, prática ou material (TALÍZINA, 1984, 1988, 1994; VYGOTSKY, 2001, 2003a, 2003b).

Vygotsky explicou que as funções intelectuais superiores e psicológicas no sujeito aparecem duas vezes, primeiro como funções interpsíquicas e depois como funções intrapsíquicas. Neste sentido, elaborou os conceitos de "zona de desenvolvimento real" e "zona de desenvolvimento proximal" de suma importância para a educação como uma ciência. Ele define que "zona de desenvolvimento proximal" como a distância entre o nível de desenvolvimento real, determinado pela capacidade de resolver um problema sem ajuda, e o nível de desenvolvimento potencial, determinado através de resolução de um problema sob a orientação de um adulto ou em colaboração com outro companheiro (2001, 2003a). 
$\mathrm{Na}$ teoria da atividade de Leóntiev (2004) o estudante se relaciona com o mundo através da atividade que está formada por ações com suas respectivas operações para alcançar um objetivo. As ações constituem a unidade principal, o objetivo e a motivação devem estar próximos para constituir uma atividade de estudo. Leóntiev reconhece nos trabalhos de Vygotsky que a atividade interna ou mental é reflexo da atividade externa ou material, mas não indica como é esta transformação.

Posteriormente Galperin indica o caminho para a transformação, não resolvida por Leóntiev, ao colocar que a atividade de estudo antes de ser mental deve passar por cinco etapas qualitativas, que são: primeira etapa, formação da base orientadora da ação; segunda etapa, formação da ação em forma material ou materializada; terceira etapa, formação da ação verbal externa; quarta etapa, formação da linguagem interna para si e a quinta etapa, formação da linguagem interna. Isto se conhece como a teoria de formação por etapas das ações mentais e os conceitos de Galperin (GALPERIN; TALÍZINA, 1967; TALÍZINA, 1984, 1988).

O processo de ensino aprendizagem deve estar sob o comando do professor seguindo os princípios da teoria geral de direção, constituída por: o objetivo de ensino, o estado de partida da atividade psíquica dos estudantes, o processo de assimilação, a retroalimentação e a correção. Este processo deve ser cíclico e transparente visando, como elemento principal, o processo de transformação da atividade externa à atividade interna (TALÍZINA, 1984, 1988, 1994).

O processo de ensino aprendizagem é realizado através da atuação conjunta de professores e estudantes, organizado sob a direção do professor, com a finalidade de prover as condições e meios pelos quais os estudantes assimilam ativamente conhecimentos, habilidades, atitudes e convicções (LIBÂNEO, 1994).

Dentro da perspectiva da teoria adotada, segundo Talízina (1988), para a construção do sistema de ações nas soluções de problemas didáticos devem realizar-se os seguintes atos: definir o objetivo de ensino da atividade de estudo, determinar o nível de partida na atividade cognoscitiva, formar a base orientadora da ação, selecionar as tarefas do processo de assimilação e os instrumentos de controle, executar a retroalimentação e correção. A seguir será detalhado cada ato. 
Sendo o objetivo de ensino o aspecto hierárquico, deve definir-se a atividade em função do mesmo, constituída por um sistema invariante de ações com suas respectivas operações. Podendo consistir na formação de uma nova atividade ou elevação da qualidade da atividade existente.

Um elemento muito importante no processo de ensino aprendizagem é o nível de partida dos estudantes, em relação à atividade cognitiva que se deseja formar, que está constituído pelo sistema de conceitos, dos métodos e a etapa mental alcançada pelo estudante. Assim garante-se conduzir o processo de ensino aprendizagem na zona de desenvolvimento proximal.

Para determinar a etapa que se encontra os estudantes tem que recorrer às características primárias e secundárias das ações. As primárias são: a forma, o caráter generalizado, explanado e assimilado e as secundárias são: o caráter razoável, consciente, abstrato e a solidez (TALÍZINA, 1998).

A base orientadora da ação deve assegurar a execução correta da ação, assim como a seleção racional pelo menos de um método de solução. Para ser eficaz ela necessita ser completa, geral e obtida de forma independente pelos estudantes.

Com frequência os professores ao orientar as ações direcionam a solução de casos particulares e os estudantes obtêm as ações preparadas pelo professor, sendo pouco efetivo na transferência dos conhecimentos para novas situações. Isto pode ser agravada em ocasiões quando as orientações não são completas (TINTORER; MENDOZA; CASTAÑEDA, 2009; MENDOZA; TINTORER, 2010).

Depois de planejada a base orientadora da ação deve-se apresentar para os estudantes o conjunto de tarefas do processo de assimilação que está constituído pelo objetivo de ensino, a atividade, o conteúdo da base orientadora e a ordem de seu cumprimento. Tudo isso permite iniciar de forma plena e transparente o processo de ensino aprendizagem.

Os instrumentos de controle devem permitir avaliar o nível alcançado na atividade formada correspondente ao objetivo de ensino, segundo o conteúdo e as etapas de formação das ações mentais dos estudantes. 
A partir dos instrumentos de controle são coletadas as informações do retorno sistemático (retroalimentação) como, por exemplo: se o estudante realiza corretamente a ação planejada e se a forma da ação corresponde à essa etapa, com ênfase no trabalho independente do estudante.

A correção do processo deve ser realizada, considerando a retroalimentação e pela lógica interna do processo de assimilação. Não deve ser realizada considerando somente o descumprimento dos elementos da ação, senão as causas que a suscitaram como: deficiência no nível de partida na atividade cognitiva, ou na etapa anterior do processo de assimilação ou causas eventuais. Também, se necessário, dar atendimento de reforço ou passar o estudante para uma etapa posterior antes do previsto, assim como avaliar o próprio programa de ensino.

\section{0 problema docente ${ }^{4}$}

Para Majmutov o caminho da construção de conhecimento no processo de ensino passa pela formulação e solução do problema docente.

O problema docente é um fenômeno subjetivo e existe na consciência do estudante em forma ideal, no pensamento, da mesma maneira que qualquer julgamento, enquanto não seja perfeito logicamente e se expresse na linguagem ou nas letras do escrito. Esta formulação linguística de um problema é o que se denomina tarefa (MAJMUTOV, 1983, p. 129). A tarefa, como categoria didática, se diferencia do problema como categoria psicológico - didático e lógica, pelo fato que ela (a tarefa) é a expressão externa do problema [...] O problema docente, como conceito independente, reflete uma esfera específica da realidade, uma etapa plenamente determinada do processo aprendizagem do estudante. Precisamente por esta razão, o problema docente é uma importante categoria psicológica - didática, cujo utilização na investigação do processo de ensino pode contribuir para a revelação de regularidades novas ou a precisão das que já se conhecem. (MAJMUTOV, 1983, p. 131).

Ele destaca a contradição como a força motriz na formação do problema docente

A contradição objetiva de uma tarefa, entre os dados e as condições, pode converter-se na força motriz do pensamento somente em caso de que se transforme na consciência do estudante, na contradição entre o conhecido e desconhecido. Por

${ }^{4}$ Neste item está fundamentado em Majmutov (1983, p. 129 - 205) 
conhecido se tem em consideração os dados da tarefa, os conhecimentos anteriores e a experiência pessoal do estudante; por desconhecido, não só aquilo que não se dá nas condições e nos objetivos, senão na incógnita, e no procedimento para alcançar o objetivo, ou seja, o método de resolver o problema. Isto significa que a tarefa, despois de receber na consciência do estudante um conteúdo novo, se transforma em um fenômeno totalmente novo, o problema docente. (MAJMUTOV, 1983, p. 132).

O problema docente determina a busca mental, motiva pela pesquisa do desconhecido, e conduze a assimilação de um novo conceito ou de um método novo da ação. Na quarta etapa de Galperin o estudante deve transitar pela formação de novos conceitos e habilidades, a partir do alcançado nas etapas anteriores propinando o desenvolvimento nível de criatividade proposto por Majmutov.

Os problemas docentes podem manifestar-se como uma categoria didática e psicológica. Os problemas docentes como categoria didática podem aparecer como problemas de uma disciplina, interdisciplinar, de uma aula, fora da aula, de ajuda, teóricos, práticos, sociológicos - práticos, científicos, para um grupo, por grupo e individual. O problema docente como categoria psicológica revela-se a partir da relação do sujeito com o objeto e da contradição do conhecido e desconhecido, enquanto a caráter de nível dificuldade, solução e sua correlação (MAJMUTOV, 1983, p. 153 - 168).

Majmutov classifica de acordo com o nível de dificuldade os problemas docentes em algorítmicos e heurísticos.

No problema algorítmico a situação de uma tarefa requer a aplicação de um algoritmo já preparado, indicando exatamente a realização de determinadas operações. Um tipo mais complexo de problema algorítmico é nos casos quando se muda a situação que condiciona modificar o algoritmo [...]. O problema heurístico surge na situação que, pelo conteúdo dos dados e o objetivo, não indica o algoritmo de solução, ou seja, há que achar o procedimento de solução, exigindo a conjetura, intuição e suposições, cuja demonstração pode realizar-se analiticamente. Geralmente o processo de solução do problema docente é uma combinação do método analítico - lógico e heurístico, no qual um problema docente que começa analítico - lógico pode-se transformar em heurístico. (MAJMUTOV, 1983, p. 160-161). 
Enquanto a solução do problema docente se destaca os problemas análogo e hipotético. O problema análogo utiliza procedimentos conhecido de solução, mas podem ser aplicados em uma situação nova relacionando uma nova combinação do conhecido e desconhecido. A analogia tem importância para a elaboração de hipóteses para as possíveis relações objetivas, motiva a busca e conduz conjetura. Os problemas hipotéticos se fundamentam nos desenvolvimentos de ideias, suposições, intuição, heurística e formulação de hipóteses que leva posteriormente a sua demonstração. (MAJMUTOV, 1983, p. 163 - 164)

O problema docente se utiliza no ensino problematizador em estreita relação com a situação problema, que constituem o momento inicial do pensamento, que provoca a necessidade cognoscitiva do estudante e cria condições internas para a assimilação em forma ativa dos novos conhecimentos e procedimentos da atividade. Dito em outras palavras, o problema docente contém dois grupos de elementos, os dados (conhecidos) e os dados novos (desconhecidos). (MAJMUTOV, 1983, p. 170 - 175)

A partir da prática pedagógica o surgimento das situações problemas podem distinguir-se quando o estudante: a) enfrenta com a necessidade de utilizar os conhecimentos assimilados anteriormente em condições de práticas novas, b) encontra uma contradição entre a via teoricamente possível para solucionar a tarefa e a impossibilidade prática do procedimento selecionado, c) encontra uma contradição entre o resultado prático alcançado na realização da tarefa docente e falta de conhecimento para dar sua fundamentação teórica e d) não conhece o procedimento para resolver a tarefa formulada em uma situação docente, quer dizer, quando o estudante toma consciência que os conhecimentos anteriores são insuficientes para explicar o fato novo. (MAJMUTOV, 1983, p. 175 - 177).

A seleção dos procedimentos para criar situações problemas depende da disciplina, do conteúdo do material docente, das particularidades individuais e das idades dos estudantes, de seu nível de preparação para resolver problemas docentes e da habilidade do professor para levar para frente o ensino problematizador (MAJMUTOV, 1983, p. 178) [...].A regra didática para a formulação do problema docente é: a) separação do conhecido e o desconhecido, b) localização do desconhecido, c) determinação das condições possíveis para a solução independente 
do problema e d) a existência de indeterminação no problema. (MAJMUTOV, 1983, p. 195).

A formulação do problema é o começo da solução, mas ela é uma atividade docente cognoscitiva com suas próprias caraterísticas. Através das pesquisas em dependência da experiência com que é resolvido o problema em relação a tarefa com caráter problematizador se pode dividir em três tipos de solução do problema docente

O primeiro tipo de solução a ser resolvido e quando não existe nenhuma experiência anterior, o estudante avança com o ensaio e erro até que uma das provas o conduz à solução [...]. No segundo tipo de solução o estudante conhece certas fórmulas e esquema mediante outro tipo de experiências. Neste caso, a solução acontece mediante o reconhecimento da situação proposta nos esquemas existentes [...]. No terceiro tipo de solução consiste que o estudante tem experiência, mas sua experiência não lhe permite resolver o problema dado. A solução consiste neste caso, que se cria sobre as bases da análise das condições da tarefa, nasce um esquema de solução que não existia com anterioridade (MAJMUTOV, 1983, p. 203 - 204) [...]. Posteriormente é realizado um plano de solução do problema que inclui a seleção de variante de solução que pode ser através de métodos analíticos ou heurísticos ou combinação de ambas. Quaisquer variantes supõem das experiências anteriores, dos conhecimentos e sua atualização e dos métodos assimilados anteriormente. (MAJMUTOV, 1983, p. 205).

\section{Atividade de situações problema e suas implicações didáticas}

Neste trabalho se define a Atividade de Situações Problema (ASP) como a Atividade de Estudo que está orientada pelo objetivo de resolver problemas docentes, na zona de desenvolvimento proximal, em um contexto de ensino aprendizagem, no qual exista uma interação entre o professor, o estudante e a tarefa com caráter problematizador; com o uso da tecnologia disponível e de outros recursos didáticos, para transitar pelos diferentes estados do processo de assimilação.

Por exemplo, a ASP em Matemática é formada por um sistema invariante de quatro ações com suas respetivas operações que permitem solucionar várias classes de problemas matemáticos. Mas que pode ser utilizada na solução de 
outros tipos de problemas docentes (MENDOZA, 2009, MENDOZA et al.,2009, MENDOZA; TINTORER, 2010).

A primeira ação é formular o problema docente. Ela é formada pelas operações: a) analisar a situação problema para determinar os elementos conhecidos e desconhecidos; estudar os dados e as condições da situação problema, b) reconhecer o buscado a partir de problema fechado (objetivo definido) ou aberto (objetivo não preciso).

A forma de colocar elementos conhecidos e desconhecidos dos problemas docentes devem expressar claramente a contradição entre eles. Assim se gera no próprio enunciado possibilidade de estimular o pensamento criador. Utilizar diversas condições para um mesmo problema permite explorar várias operações, permitindo recorrer a zona de desenvolvimento proximal de forma mais adequada. Por outro lado, diferenciando o buscado do desconhecido estimula ainda mais o desenvolvimento mental.

A segunda ação é construir o núcleo conceitual as operações são: a) ativar o nível de partida dos estudantes relacionado com os conhecimentos sobre o elemento conhecido e sua atualização se for necessário e b) encontrar nexos entre os conhecidos e desconhecido desde os pontos de vista conceitual e procedimental através de novas tarefas mais simples como realização de experimentos, analogia, intuição e suposição de hipóteses.

A terceira ação solucionar o problema docente formado pelas operações: a) aplicar o método lógico - analítico ou heurístico ou combinação de ambos para determinar os nexos entre o conhecido e desconhecidos e b) determinar o buscado.

A última, a quarta ação é interpretar a solução, está constituída pelas seguintes operações: a) verificar se a solução corresponde com o buscado e as condições do problema e b) analisar os resultados obtidos para encontrar possíveis novas relações conceitual e/ou procedimental com elementos anteriormente conhecidos.

Esta ação é importante para consolidar a aprendizagem consciente pois ela só é possível executá-la utilizando a linguagem conceitual da ciência, além de permitir explorar novos problemas de forma mais eficiente. 
Na figura 1 se pode observar a integração da ASP, as etapas de formação das etapas mentais e conceitos e a direção da ASP. A partir da definição do objetivo de ensino deve-se determinar o nível de partida dos estudantes. Seguidamente deve-se planejar a Base Orientadora da Ação da Atividade de Situações Problema. O professor deve garantir as tarefas necessárias para a realização com êxito de cada etapa do processo de assimilação, assim como a realização da retroalimentação com suas respetivas correções. Ele deve orientar para a solução da contradição do conhecido e desconhecido, se for necessário atualizar o conhecido.

Figura 1 - Direção da Atividade de Situações Problema (ASP)

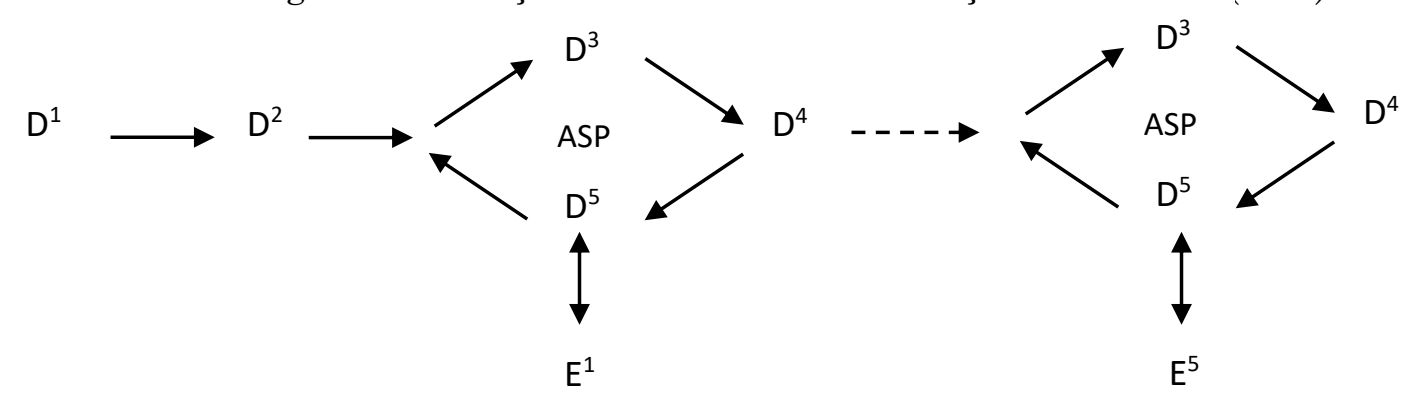

Fonte: Mendoza, 2009

\section{Legendas}

$\mathrm{D}^{1}$ : o objetivo de ensino, $\mathrm{D}^{2}$ : o estado de partida da atividade psíquica dos estudantes, $\mathrm{D}^{3}$ : o processo de assimilação, $\mathrm{D}^{4}$ : a retroalimentação e $\mathrm{D}^{5}$ : a correção.

ASP: Atividade de Situações Problema

$\mathrm{E}^{1}$ : formação da base orientadora da ação

$---\rightarrow$ : Etapas das ações mentais entre $\mathrm{E}^{1}$ e $\mathrm{E}^{5}$ e com as mesmas estruturas cíclicas das etapas mencionadas. As intermediarias são: $\mathrm{E}^{2}$ : formação da ação em forma material ou materializada; $\mathrm{E}^{3}$ : formação da ação verbal externa; E4: formação da linguagem interna para si.

$\mathrm{E}^{5}$ : formação da linguagem interna

No primeiro momento deve-se identificar o contexto que vai ser enfrentado pelo professor. Sem dúvida é primária, pois ela permite iniciar a atividade na direção certa. Com frequência a situação didática é apenas reconhecida como determinada pelo estudante e/ou a carência de recursos didáticos na escola, o que leva a que o professor não se sinta responsável pela solução e, por conseguinte espere que a direção da escola ou as famílias dos estudantes tratem de resolver o problema. 
O domínio pelo professor dos conteúdos, de como organizar o sistema de ações e como utilizar os métodos mais adequados são essenciais para tratar de atingir os objetivos de ensino. Deve-se reconhecer que em muitas ocasiões identificar a atividade cognoscitiva necessitará de entender profundamente experiências já realizadas ou realizar pesquisas próprias, sobretudo quando se deseja desenvolver uma nova atividade. No caso que se deseje elevar o nível de alguma característica de uma atividade que já vem sendo trabalhada, então o foco será apenas essa característica.

Não basta identificar os conhecimentos conhecidos relacionados com os novos conteúdos a serem trabalhados, se precisa também determinar as capacidades para executar as ações e os métodos. A não consideração desses outros elementos pode explicar a situação frequente de que os estudantes dominando os conteúdos não consegue aplicá-los a novas situações.

Considerando que, para assimilar o conhecimento se deve passar pelas etapas proposta por Galperin, então é necessário determinar em que etapa mental se encontra o estudante para iniciar a atividade ou continuá-la. Utilizar diversos instrumentos de diagnóstico, que a sua vez, devem ser avaliados com vista a seu aperfeiçoamento para futuras determinações do nível de partida dos estudantes.

A determinação da atitude e motivação dos estudantes para a atividade deve manter-se durante todo o processo e não apenas neste primeiro momento, pois uma atividade nova pode ser atrativa inicialmente, mas com o tempo os estudantes podem perder motivação, e sem motivação a atividade se converte em ação apenas.

O planejamento da Atividade de Situações Problema está estreitamente relacionado com a formulação do sistema invariante das ações, é um momento de decisões para o professor analisar de forma imediata os resultados das ações anteriores. Deve decidir como levar os estudantes da zona de desenvolvimento real à potencial. É o momento de construir a zona de desenvolvimento proximal.

Não se descarta atendimento diferenciado para alguns estudantes que dado seu nível de partida estão muito longe das necessidades impostas pelos objetivos de ensino e podem colocar em risco o desenvolvimento do resto dos 
estudantes. É bom lembrar que um ensino que apenas trabalhe com os estudantes na zona de desenvolvimento real não os desenvolve.

A construção do sistema de ações invariantes é uma ação complexa que depende dos objetivos de ensino dirigidas a aumentar a eficiência do processo de aprendizagem, pois os estudantes estarão melhor preparados para resolver maiores números de situações. Talízina (1988) explica várias situações de ensino pesquisadas em condições reais que permitem entender como construir este sistema, ainda que se precisa de professores bem preparados tecnicamente e pedagogicamente e com alguma experiência na execução desta ação. Para os iniciantes se recomenda aproveitar experiências relatadas na literatura que podem ser avaliadas após sua execução para seu aperfeiçoamento. $\mathrm{O}$ trabalho coletivo pode ajudar a diminuir a dificuldade para executar a ação.

Formular a base orientadora da ação (BOA) necessita considerar os objetivos de ensino e o nível de partida dos estudantes. É necessário selecionar as estratégias concretas para orientar as ações da atividade, que deve ser sempre plena e a mais geral possível ainda que em alguns casos possa ser preparada pelo professor ou com maior participação dos estudantes.

Recomenda-se utilizar como critério para decidir o modo de obtenção da BOA o caráter essencial da atividade dentro dos objetivos gerais do sistema de ensino, pois uma BOA obtida independentemente pelos estudantes deve consumir mais tempo que uma preparada pelo professor. Sem dúvida outros critérios podem ser utilizados como a preparação do professor e os recursos disponíveis na escola para a execução da etapa.

$\mathrm{Na}$ seleção de recursos didáticos, se busca um auxiliar para garantir um processo de ensino mais eficiente, sempre que selecionados coerentemente com a teoria de aprendizagem adequada e as exigências da teoria geral da direção.

Recursos didáticos que não garantam, por exemplo, a etapa material ou materializada não devem ser utilizados, mas esses mesmos recursos podem ser úteis nas etapas de generalização e automatização. Por exemplo, o uso do computador na resolução de problemas que envolvem sistema de equações lineares pode influenciar negativamente quando o estudante está-se apropriando 
dos procedimentos matemáticos para a solução do sistema aplicando matrizes. Quando assimilados esses procedimentos é recomendável utilizar o computador para realizar os numerosos cálculos mecânicos na resolução de sistema de equações lineares e aproveitar o tempo disponível para aprimorar a ação de interpretar os resultados do problema assim como, trabalhar problemas mais complexos, ou seja, potencializar a generalização.

Ao selecionar o sistema de avaliação é importante considerar a etapa de formação das ações mentais em que se encontra o estudante. A avaliação deve ser contínua, combinada com uma inicial e final, mas a mais efetiva é a sistemática que permite realizar a correção do processo de ensino aprendizagem.

Primeiramente deve-se realizar um diagnóstico inicial relacionado com objetivo de ensino para conhecer o nível de partida dos estudantes, com estas informações se elabora a BOA. Na etapa material e verbal o controle das ações deve ser detalhado através da interação estudante - professor na sala aula, provas de lápis e papel ou de forma que seja adequada. Na etapa verbal externa para si o controle deve ser esporádico ao pedido do estudante. Deve-se realizar uma avaliação final para verificar o cumprimento do objetivo de ensino

O sistema de avaliação deve servir como forma de controle de todo o processo de ensino e de aprendizagem para poder realizar os ajustes necessários durante todo o processo e não apenas ao final. A variável fundamental é a qualidade da etapa mental do estudante. Assim na BOA a avaliação deve ser dirigida para a compreensão das orientações. Se a BOA, quando executada não satisfaz as exigências propostas deve ser corrigida até que seja assimilada pelos estudantes; pois para garantir a aprendizagem o estudante deve passar por todas as etapas. Sendo que as etapas de generalização e automatização ficam limitadas pelos objetivos de ensino.

Talízina (1988) considerando um conjunto de pesquisas realizadas chega as seguintes conclusões sobre a forma de organizar a avaliação: nas primeiras etapas do processo de assimilação o controle deve realizar-se por operações e de forma sistemática. Nas duas últimas etapas deve ser esporádico e a pedido do estudante. $\mathrm{O}$ controle mútuo entre estudantes contribui para incentivar a motivação positiva entre eles. 
Entra-se no momento de construir a ASP e se começa com preparação do plano de ensino, como havia sido comentado o processo de ensino e aprendizagem deve ser centrado na resolução de problema, ou seja, ela é considerada como o ponto inicial para a assimilação dos conteúdos. Para realizar o plano de ensino deve ser considerado a lógica e características dos conteúdos matemáticos e as etapas mentais. Sugerem-se para sua construção analisar os seguintes elementos: conteúdos, objetivos, tipo de aulas, horas aulas e etapas mentais. Ao realizar os planos de aulas deve-se manter a coerência com os princípios teóricos expostos enquanto a formação das etapas mentais e a direção da ASP

Ao preparar os instrumentos do sistema de avaliação, deve-se considerar a etapa de formação das ações mentais e os conteúdos. As provas de lápis e papel podem ser utilizadas em todas as etapas, devem ser questões subjetivas onde tenham com frequência a pergunta "Justifique sua resposta", ou seja, é importante a argumentação das respostas. Outra prova muito interessante são as avaliações orais, sugere-se preferencialmente na etapa verbal externa.

A observação direta na sala de aula será um instrumento muito valioso para compreender o processo de aprendizagem dos estudantes, o que poderá produzir mudanças posteriores nos instrumentos a serem utilizados.

É necessário utilizar instrumentos de controle sobre os resultados dos estudantes em cada ação para retroalimentar o processo e fazer as correções necessárias. É importante salientar que o momento mais complexo é a solução do problema docente quando é possível que a construção do núcleo conceitual não seja suficiente para o cumprimento da atividade. A ampliação dos conhecimentos na resolução de problemas permite aumentar a possibilidade de sucesso.

A ASP é um procedimento que pode resolver muitos problemas que tenham, principalmente, modelos matemáticos. Os conhecimentos prévios dos estudantes e suas habilidades na resolução de problemas são sugeridos de acordo com a complexidade dos conteúdos matemáticos a serem assimilados, começando pela a orientação das ações da ASP por problemas heurísticos e não por situaçõesproblema. 
A continuação se apresenta um exemplo no tema resolução de sistema de equações lineares vinculado aos últimos anos do Ensino Fundamental.

Uma empresa agrícola deve vender 170 toneladas de legumes entre cenoura e batata, desejando obter $R \$ 231000$ de renda. Se por cada hectare cultivada de cenoura se produz 3 toneladas e por cada hectare de batata 4 toneladas e a renda obtida por cada tonelada vendida de cenoura é de $\mathrm{R} \$ 1500$ e por cada tonelada de batata $R \$ 1200$. Determine a quantidade de hectare a ser cultivada de cada tipo. Considerando que cada condição do problema pode ser escrita em linguagem matemático como uma equação.

Aplicando a ASP para realizar a primeira ação, formular o problema docente, se deve determinar os elementos conhecidos e os desconhecidos, os dados e as condições da tarefa como a primeira operação.

Após da leitura da tarefa se solicita aos estudantes que tentem expressar sua compressão podendo destacar alguns termos como tonelada: Sistema métrico, medida de peso equivalente a $1000 \mathrm{~kg}$, simbolizado ton; hectare: Unidade de medida agrária equivalente a 10000 metros quadrados, simbolizado por $\mathrm{h}_{\mathrm{a}}$; renda: certa quantia de dinheiro obtida pela venda de um produto ou serviço, simbolizado em $\mathrm{R} \$$; rendimento agrícola: toneladas/hectare, quantidade de toneladas produzida de cada cultivo por hectare, denotado por ton/ha; $\underline{\text { rendimento }}$ comercial: reais/toneladas, renda em reais pela venda de cada tonelada, denotado por $\mathrm{R} \$ /$ ton.

A tarefa se caracteriza porque todos os dados estão explicitados sendo que: a empresa agrícola cultiva cenouras e batatas e quer vender 170 toneladas; pelas vendas da produção de 170 toneladas entre cenouras e batatas querem obter 231000 reais de renda; por cada hectare cultivada de cenouras são produzidas 3 toneladas; por cada hectare cultivada de batatas são produzidas 4 toneladas; quando é vendida uma tonelada de cenouras obtemos 1500 reais de renda; e quando é vendida uma tonelada de batatas obtemos 1200 reais de renda.

O elemento desconhecido é determinar a quantidade de hectare que devemos cultivar de cenouras e de batatas e que cumpra com todas as condições podendo expressar-se em termos matemáticos como as variáveis, $\mathrm{x}_{1}$ que representa a quantidade de hectare a ser cultivada de cenouras, denotado por 
$\mathrm{x}_{1} \mathrm{~h}_{\mathrm{a}}$ e $\mathrm{x}_{2}$ que representa a quantidade de hectare a ser cultivada de batatas, denotado por $\mathrm{x}_{2} \mathrm{~h}_{\mathrm{a}}$.

Como segunda operação se identifica que é um problema fechado onde o desconhecido coincide com o buscado, expressado no objetivo do problema.

A segunda ação, construir o núcleo conceitual, na primeira operação será necessário verificar o nível de partida dos estudantes para a construção de equações que expressem em linguagem matemática cada condição. Essa discussão depende de cada turma, mas se pode destacar os seguintes elementos:

Se por cada hectare cultivada de cenoura são produzidas 3 toneladas então $3 \mathrm{x}_{1}$ representa a quantidade de cenoura a ser produzida, $3 \frac{\text { ton }}{h_{a}} x_{1} h_{a}=3 x_{1}$ ton; se por cada hectare cultivada de batatas são produzidas 4 toneladas então $4 \mathrm{x}_{1}$ representa a quantidade de batatas a ser produzida, $4 \frac{\text { ton }}{h_{a}} x_{2} h_{a}=4 x_{2}$ ton; como a empresa agrícola quer vender 170 toneladas entre cenoura e batatas então $($ toneladas de cenouras $)+($ toneladas de batatas $)=($ toneladas total da empresa $)$ representado por $3 x_{1}+4 x_{2}=170$. Esta equação representa a produção total em toneladas.

Outra condição está relacionada com a renda, se por uma tonelada vendida de cenoura se obtém 1500 reais de renda; como são produzidas 3 toneladas então é $3 x(R \$ 1500)=R \$ 4500$, então $4500 x_{1}$ reais é a renda pela venda de cenouras; $\left(3 x_{1}\right.$ ton $)\left(1200 \frac{R \$}{\text { ton }}\right)=R \$ 4500 x_{1}$ e uma tonelada vendida de batatas obtém 1200 reais de renda; como são produzidas 4 toneladas então é $4 \mathrm{x}(\mathrm{R} \$ 1200)=\mathrm{R} \$ 4800$ então $4800 \mathrm{x}_{2}$ reais é a renda pela venda de batatas $\left(4 x_{2}\right.$ ton $)\left(1200 \frac{R \$}{t o n}\right)=R \$ 4800 x_{2}$. Se quer obter $R \$ 231000$ de renda total pelas vendas da produção de batatas e cenouras, então (renda em reais da produção de cenoura) + (renda em reais da produção de batatas $)=($ renda total em reais da produção), é representado pela equação $4500 x_{1}+4800 x_{2}=231000$. Esta equação representa a renda em reais da produção da empresa agrícola. 
- Podemos resumir

\begin{tabular}{|c|c|c|c|}
\cline { 2 - 4 } \multicolumn{1}{c|}{} & Cultivo de cenouras & Cultivo de batatas & Total \\
\hline Toneladas (ton) & $3 \mathrm{x}_{1}$ ton & $4 \mathrm{x}_{2}$ ton & 170 ton \\
\hline Rendas $(\mathrm{R} \$)$ & $\mathrm{R} \$ 4500 \mathrm{x}_{1}$ & $\mathrm{R} \$ 4800 \mathrm{x}_{2}$ & $\mathrm{R} \$ 231000$ \\
\hline
\end{tabular}

$\mathrm{O}$ sistema fica representado por

$\left\{\begin{array}{l}3 x_{1}+4 x_{2}=170 \\ 4500 x_{1}+4800 x_{2}=231000\end{array}\right.$

A segunda operação desta ação é encontrar os nexos conceituais e procedimentais entre as soluções de uma equação (o conhecido) e a solução do sistema (o desconhecido). A solução do sistema formado pelas duas equações lineares deve ser, também, a solução de todas as referidas equações. Para resolver o sistema pode-se utilizar o método da substituição que consiste em isolar uma variável em uma das equações e proceder a substituição na outra equação.

$\mathrm{Na}$ primeira operação da terceira ação, solucionar o problema docente, se aplica o método lógico encontrado anteriormente que permite determinar o buscado como segunda operação. Assim, $\mathrm{x}_{1}=30 \mathrm{~h}_{\mathrm{a}}$ e $\mathrm{x}_{2}=20 \mathrm{~h}_{\mathrm{a}}$.

$\mathrm{Na}$ quarta ação, interpretar a solução, primeiramente se verifica se a solução corresponde ao buscado e corresponde as condições do problema. Assim, como ao plantar 30 hectares se obter 90 toneladas de cenouras e ao plantar 20 hectares de batatas se obtém 80 toneladas de batatas o agricultor alcançará 170 toneladas como o previsto. Vendendo essa produção ele obtém $\mathrm{R} \$ 135000$ pelas cenouras e $\mathrm{R} \$ 96000$ pelas batatas, ou seja, $\mathrm{R} \$ 231000$ no total segundo a condição do problema.

Considerando outro tipo de problema docente que explora a contradição entre os resultados experimentais e a teoria científica que possuem os estudantes é possível utilizar os problemas experimentais para trabalhar a modelação. Este procedimento didático pode ser utilizado em laboratórios reais ou virtuais, este último simulando o comportamento do objeto em estudo que permitam a interação estudante máquina. O professor orienta os estudantes a realizar experimentos manipulando variáveis e medindo outras, utilizando procedimentos 
lógicos - analíticos, vão construindo tabelas e gráficos e chegando a conclusões parciais que possibilitam construir os fundamentos teóricos que faltam a partir dos objetivos de ensino. O professor orienta considerando a zona de desenvolvimento proximal de seus estudantes, mas permitindo que eles trabalhem de forma independente.

Outra situação problema cuja solução inclui o procedimento heurístico pode ser apresentada ao analisar dois movimentos por trajetórias diferentes, desde o mesmo ponto inicial até o mesmo ponto final. Por exemplo, numa gincana, dois competidores tentam alcançar primeiro um objeto que se encontra na base de um pequeno prédio partindo da laje do prédio. Um competidor decide deixar-se cair e ou outro corre pela escada do prédio. É possível demostrar utilizando o método lógico - analítico que o primeiro realiza um movimento retilíneo uniformemente acelerado com a aceleração da gravidade (aproximadamente $9,8 \mathrm{~m} / \mathrm{s}^{2}$ ). Continuando o procedimento lógico se chega a conclusão que, como a trajetória da corrida pela escada resulta mais cumprida, o segundo competidor deve realizar a descida com uma aceleração maior que a aceleração da gravidade. A questão agora é que os estudantes não têm procedimentos analíticos que permitam estabelecer se isso é possível ou não, portanto, necessita-se intuir algum caminho de solução. Neste caso é possível buscar dados experimentais acessíveis como, por exemplo, as performances de corredores profissionais. Sabe-se que eles percorrem distâncias de $100 \mathrm{~m}$ em tempos menores aos 10 segundos. Continuando o procedimento analítico se chega a conclusão de que isso significa uma aceleração média de aproximadamente $2 \mathrm{~m} / \mathrm{s}^{2}$, bem inferior a aceleração da gravidade. Assim se chega a que a equipe cujo representante se deixa cair livremente deve ganhar a gincana.

No Brasil, pode-se encontrar algumas pesquisas utilizando as ideais de Galperin e Majmutov no ensino de ciências e matemática (CHIRONE, 2016; MATOS, 2016; SILVA, 2014; SILVA, 2016)

\section{Conclusões}


A partir da teoria Histórico-Cultural o ensino problematizador é uma alternativa didática que mobiliza uma quantidade considerável de processos cognitivos, contribuindo para a melhoria na qualidade da aprendizagem. Quando se considera o processo de assimilação proposto por Galperin, utilizar essa metodologia na BOA permite orientar aos estudantes na Atividade e logo situálos num ambiente de exercitar de maneira consciente os procedimentos analíticos e/ou heurísticos, para mais tarde aplicá-los a novas situações, o que promove o desenvolvimento da criatividade dos estudantes.

Majmutov, além de fazer uma detalhada fundamentação filosófica, psicológica e didática do ensino problematizador apresenta com precisão como construir o problema docente, seus diferentes tipos e chegar a sua solução, contribuindo significativamente para o trabalho docente de excelência.

Assim, se recomenda utilizar a teoria de Galperin para organizar todo o processo de aprendizagem na zona de desenvolvimento proximal e dirigir o trabalho de problematização segundo Majmutov. Conclui-se que, ambos teóricos coincidem em que o sucesso do processo de ensino aprendizagem é promovido por uma combinação de ações reprodutivas e criativas no trabalho independente dos estudantes.

\section{Referências}

CHIRONE, A. R. R. A aprendizagem de equações do $1^{\circ}$ grau a partir da Atividade de Situações Problema como metodologia de ensino, fundamentado na teoria de formação por etapas das ações mentais e conceitos de Galperin. Boa Vista, 2016. Dissertação (Mestrado em Ensino de Ciências) - Universidade Estadual de Roraima.

GALPERIN, P. Y.; TALÍZINA, N. F. La formación de conceptos geométricos elementales y su dependencia sobre la participación dirigida de los alumnos. In: Psicología Soviética Contemporánea: Selección de artículos científicos. La Habana: Ciencia y Técnica, 1967, p. 272-301.

LEONTIEV, A. O desenvolvimento do psiquismo. 2. ed. São Paulo: Centauro, 2004.

LIBÂNEO, J. C. Didática. São Paulo: Cortez, 1994. 
MAJMUTOV, M. J. La Enseñanza Problémica. Habana: Pueblo y Revolución, 1983.

MATOS, V. G. S. A Atividade de Situações Problema na experimentação em ambientes virtuais como ferramentas de aprendizagem de óptica, fundamentada na teoria de formação por etapas das ações mentais de Galperin, nos estudantes do $2^{\circ}$ Ensino Médio. Boa Vista, 2016. Dissertação (Mestrado em Ensino de Ciências) - Universidade Estadual de Roraima.

MENDOZA, H. J. G. Estudio del efecto del sistema de acciones en el proceso de aprendizaje de los alumnos en la actividad de situaciones problemas en Matemática, en la asignatura de Álgebra Lineal, en el contexto de la Facultad Actual de la Amazonia. 269 f. Teses (Doctorado en Psicopedagogía) - Facultad de Humanidad y Ciencia en la Educación. Universidad de Jaén, 2009.

. et al. La teoría de la actividad de formación por etapas de las acciones mentales en la resolución de problemas. Revista Inter Sciencie Place, Rio de Janeiro, n. 9, set. - out. 2009.

; TINTORER, O. Formação por etapas das ações mentais na Atividade de Situações Problema em Matemática. In: X Encontro Nacional de Educação Matemática (X ENEM): Salvador, 2010.

RUBINSTEIN, J. L. Principios de Psicologia General. Habana: Revolucionaria, 1967.

SILVA, J. C. Desenvolvimento do pensamento criativo em estudantes de Medicina da UFRR, fundamentado no ensino problematizador de Majmutov. Boa Vista, 2016. Dissertação (Mestrado em Educação). Universidade Estadual de Roraima.

SILVA, L. L. F. A experimentação na resolução de problemas como ferramenta pedagógica no ensino de Física. Boa Vista, 2014. Dissertação (Mestrado Ensino de Ciência). Universidade Estadual de Roraima.

TALÍZINA, N. Conferencias sobre "Los Fundamentos de la Enseñanza en la Educación Superior”. Universidad de la Habana, 1984.

La teoría de la actividad de estudio como base de la didáctica en la educación superior . México, DF: Universidad Autónoma Metropolitana, 1994.

. Psicología de la Enseñanza. Moscú: Progreso, 1988.

TINTORER, O.; MENDOZA, H. J. G.; CASTAÑEDA, A. M. M. Implicação da base das ações e direção do processo de estudo na aprendizagem dos alunos na Atividade de Situações Problema em sistema de equações lineares. In: VIII 
Congresso Norte Nordeste de Educação em Ciência e Matemática: Boa Vista: UERR, 2009.

VYGOTSKY, L. S. A construção do Pensamento e da Linguagem. São Paulo: Martins Fonte, 2001. . A formação Social da Mente. São Paulo: Martins Fontes, 2003a. Pensamento e Linguaguem. São Paulo: Martins Fontes, 2003b.

Recebido em maio de 2017. Aprovado em março de 2018. 